\title{
Oral and Oropharyngeal Cancer in Mosul City in 2005
}

Hadeel S Alazzawi BDS, MSc

Ayad H Al-Ramadhani FRCS, FICS, FICA

\author{
Ninevah Health Directorate \\ Ministry of health \\ Ninevah Health Directorate \\ Ministry of health
}

\begin{abstract}
Aim: To evaluate oral cancer status in Mosul during 2005 that will help planning research, prevention, and treatment measures. Materials and Methods: Data on oral cancer cases treated in Mosul city hospitals during 2005 were collected. These cases included patients who were residents in Mosul city only. The study covers the site, clinical presentation, histopathological, and methods of treatment of fore mentioned malignancy. Results: Thirty one new cases diagnosed in Mosul hospitals were included in this study. The Male to female ratio was $2.4: 1$. About $58 \%$ of patients were over sixty years of age. The most common site affected the lip (22.6\%). Histologically, squamous cell carcinoma was the most common representing $64.5 \%$ of cases examined. Metastasis to regional lymph nodes was present in $74.2 \%$ of cases. Conclusion: In Mosul, oral cancer is rare. The cases of this study were detected in advanced stages affecting the choice of therapy and making prognosis much worse.

Key wards: oral, oropharyngeal, cancer, Mosul.
\end{abstract}

Alazzawi HS, Al-Ramadhani AY. Oral and Oropharyngeal Cancer in Mosul City in 2005. Al-Rafidain Dent J. 2009; 9(1): 90-93.

Received: $12 / 11 / 2007 \quad$ Sent to Referees: $13 / 11 / 2007$

Accepted for Publication: 9/3/2008

\section{INTRODUCTION}

The estimated number of new cancer cases each year worldwide is expected to rise from 10 million in 2000 to 15 million by 2020 . Some $60 \%$ of all new cases will occur in less developed parts of the world (1). Worldwide oral cancer is the eleventh most common cancer (2), and oral carcinoma is one of the 10 most common causes of death ${ }^{(3)}$.

Cancer statistics constitute the basis of good cancer program at a local level that helps in early recognition and diagnosis. This is mandatory in improving survival rate and limiting the complicated therapy, to compare cancer pattern and links that can be prevented or altered, to help keeping cancer burden under control and lessen its bad effects on our people and society $^{(1)}$.

Understanding and controlling malignant disease has very broad dimensions. It requires a competent management and the best use system of available resources for planning, implementation and evaluating disease control strategies. Epidemiological studies have provided a good evidence that a number of etiological factors are implicated in the oral cancers in different anatomical sites of oral cavity ${ }^{(1,2,4)}$.

Oral cavity cancer may arise from buccal mucosa, retromolar triangle, alveolus, hard palate, anterior two third of tongue, floor of mouth and mucosal surface of the lip. Oropharyngeal cancer includes tumours of the base of tongue, vallecula, tonsil and tonsillar fossa, posterior wall and the inferior surface of the soft palate and uvula ${ }^{5}$. Cancers of the oral mucosa and oropharynx can be considered together, as there are similarities in their epidemiology, treatment and prognosis ${ }^{(2)}$.

\section{MATERIALS AND METHODS}

The conducted study included all oral cancer cases who are resident in Mosul and treated at Mosul hospitals viz; ALJumhory, AL-Salaam and Oncology and Nuclear Medicine Hospitals during 2005. The information collected from case sheet 
of cases in these hospitals. Then data included number of new cases, incidence rate, sex, age, site, clinical presentation, histopathological classification and method of treatment. This is the first retrospective study of oral cancer cases and their clinical review to give an idea about oral cancer in this city. We found that case records of oral cancer patients treated at Mosul hospitals were deficient in some data.

\section{RESULTS}

The total number of oral cancer patients treated at Mosul hospitals in 2005 was 55 cases including 31 patients resident of Mosul city and 24 who came from other provinces.

Among patients who are resident in Mosul, 12 (38.7\%) came from Mosul city itself, while 19 (61.2\%) came from neighboring towns, villages and countryside.

There were 22 males and 9 females (male: female ratio is 2.4:1). The highest number of oral cancer cases18 (58\%) occurred in the seventh and eighth decade of life, (table1).

Table 1: Age and sex distributions of oral cancer patients.

\begin{tabular}{lccc}
\hline Years & Males & Females & Total \\
\hline $\mathbf{0 - 9}$ & 0 & 0 & 0 \\
$\mathbf{1 0 - 1 9}$ & 1 & 1 & 2 \\
$\mathbf{2 0 - 2 9}$ & 2 & 0 & 2 \\
$\mathbf{3 0 - 3 9}$ & 1 & 1 & 2 \\
$\mathbf{4 0 - 4 9}$ & 2 & 0 & 2 \\
$\mathbf{5 0 - 5 9}$ & 3 & 2 & 5 \\
$\mathbf{6 0 - 7 0}$ & 5 & 1 & 6 \\
$\mathbf{7 0 -}$ & 8 & 4 & 12 \\
\hline Total & 22 & 9 & 31 \\
\hline
\end{tabular}

The most common site of oral cancer was lips $(22.6 \%)$. Tongue, salivary gland and tonsils with the same percentage (12.9\%) (table 2).
Table 2: Site of oral cancer

\begin{tabular}{lcc}
\hline \multicolumn{1}{c}{ Site } & No. & $\%$ \\
\hline Lips & 7 & 22.6 \\
Tongue & 4 & 12.9 \\
Major salivary glands & $\varepsilon$ & 1 r.9 \\
Tonsils & 4 & 12.9 \\
Gum & 3 & 9.7 \\
Floor of the mouth & 2 & 6.5 \\
Mandible & 2 & 6.5 \\
Alveolar ridge & 1 & 3.2 \\
Palate & 1 & 3.2 \\
Maxilla & 1 & 3.2 \\
Cheek & 1 & 3.2 \\
Chin & 1 & 3.2 \\
\hline Total & 31 & 100.0 \\
\hline
\end{tabular}

Clinically, the main presenting signs and symptoms were; mass in 11 cases, ulcer in 4 cases, both (mass and ulcer) in 3 cases, other cases were unrecorded in the case sheets. Other clinical features were pain in 3 cases, facial swelling in 3 cases, teeth mobility in 2 cases, limitation of mandibular movement in 2 cases, and trismus in 1case. Twenty three (74.2\%) of these patients came to the hospitals with lymphadenopathy. One patient only did not have lymph node involvement; and in 7 patients the lymph node status was not recorded.

Table (3): Histological types of oral cancer and their incidence:

\begin{tabular}{ccc}
\hline Histology & No. & \% \\
\hline Squamous cell carcinoma & 20 & 64.5 \\
NHL & 4 & 12.9 \\
Adenocarcinoma & 4 & 12.9 \\
Rhambdosarcoma & 2 & 6.4 \\
Verrucous carcinoma & 1 & 3.2 \\
\hline Total & 31 & 100.0 \\
\hline
\end{tabular}


Histologically, the most common type was squamous cell carcinoma $64.5 \%$ then non Hodgkin's lymphoma 12.9\%, adenocarcinoma $12.9 \%$, rhambosarcoma $6.4 \%$, and verrucous carcinoma $3.2 \%$ (table 3). The histological degree of differentiation is shown in (table 4).
Concerning, most of the cases [21 $(67.7 \%)$ ] were treated by chemotherapy and/or radiotherapy, while 7 (22.5\%) were treated by radical surgery like mandibellectomy, glossectomy and/or maxillectomy.

Table 4: Degree of histological differentiations

of oral Squamous cell carcinoma

\begin{tabular}{|c|c|c|c|c|}
\hline Well & Moderate & Poor & Unrecorded & Total \\
\hline 8 & 6 & 4 & 3 & 21 \\
\hline
\end{tabular}

\section{DISCUSSION}

According to Mosul Cancer Registry ${ }^{6}$, the recorded number of all type of cancer cases registred in Mosul during 2005 was 1106. Out of this total number, oral and oropharyngeal cancer cases were 21 cases $(1.8 \%)$. This difference in the recording is related to the fact that some patients were diagnosed in Mosul city hospitals, but prefered treatment outside these hospitals and vice versa as this study recorded cases only that were diagnosed and treated in Mosul.

In 1997, oral cavity tumors represented $2.7 \%$ of all cancer cases in Iraq according to Iraqi Cancer Registry ${ }^{7}$. It is rare in comparison with other cancers of the breast, lung, bronchus, bladder and lymphatic system ${ }^{6,7}$. Although regional variations do exist, in most parts of the world oral cancer is uncommon, with the exception of the Indian subcontinent where the figure reaches $40 \%$ of all malignancies. In the United Kingdom and the United States however, oral cancer accounts for $2-3 \%$ of all malignant tumors ${ }^{2,4}$.

In recorded the sex predilection the male: female ratio was 2.4:1 and is similar to other studies ${ }^{1,2}$. As shown in this study, oral cancer is a male disease, the reason is unknown but it is may be due to many factors. Tobacco smoking has been implicated as a cause and is far more common in male than female in this region ${ }^{2-4}$. Oral cancer is a disease of the elderly having a peak incidence over the seventh decades ${ }^{3-5}$. The increasing incidence of oral cancer is clearly age related. This may reflect declining immune surveillance with age and the duration of exposure to initiators and promoters to genetic events that result in malignant change. These include exposure to chemical irritants, physical irritants, viral infection, hormonal effects, cellular aging, and decreased immunologic surveillance ${ }^{3}$.

The most important factor in the survival is the stage of disease at the time of diagnosis ${ }^{2,3}$. The majority of oral cancer cases in this study presented after becoming symptomatic, thus represent a poor survival rate. The survival rates may be conditioned by the physical and social environment, lack of knowledge, risk promoting life style, attitude and behavior and limited access to health care. At least half the difference in survival in the poor has been attributed to late diagnosis.

Local or regional spread of oral carcinoma is common and affects the choice of therapy and prognosis. Unfortunately $74.2 \%$ of our patients had lymphadenopathy which mean a negative prognostic factor $2,3,5$.

\section{CONCLUSION}

The cases detected were in the advanced stages making prognosis much worse. The suffering is compounded by the high cost and centralised distribution of maxillofacial surgery, chemotherapy, and radiotherapy and the scarcity of palliative care.

Therefore further research is needed in epidemiology, pathogenesis, etiology, 
prevention, diagnosis and management of oral cancer in this country.

\section{REFERENCES}

1. World Health Organization: national cancer control programmes, polices and managerial guidelines. 2nd edition, Geneva, 2002

2.Stewart BW., and Kleihuse P.: Head and neck cancer. In WHO World Cancer Report. IARC press. Lyon, 2003:232-6.

3. Epistein JB.: Oral cancer. In: Burket's oral medicine, diagnosis and treatment. Greenberg M. and Glick M. (eds.). BC Decker Inc. Spain, 2003:194-234

4.Henk JM. and Langdon JD.: Epidemiology and aetiology. In: malignant tumors of the oral cavity. Edward Arnold. London, 198; Pp: 1,2.

5. Seeley RR, Stephens TD, Tate P. Essentials of Anatomy and Physiology. 5th ed. McGrawttill press. USA. 2005; Pp:454-488.

6.Ismail AM. and Al-Ramadhani AH.: Cancer in Mosul, incidence and mortality results of Mosul cancer registry; Mosul Continuing Medical Education Center, Directorate of Health in Ninawa. Mosul, 2005

7.Iraqi Cancer Board, Iraqi Cancer Registry Center: Results of Iraqi cancer registry 1995-1997. Ministry of Health. Baghdad, 1999. 